\title{
Sobre la Evaluación Escolar y su Ética
}

\author{
José F. Agudelo-Torres ${ }^{(1)^{*}}$, Farley S. Rojas-Restrepo ${ }^{(2)}$, Edgar Ocampo-Ruiz ${ }^{(3)}$, Sandra J. Clavijo-Zapata ${ }^{(4)}$ \\ (1) Facultad de Educación y Humanidades, Univ. Católica Luis Amigó, Trans 51a67B-90, Medellín-Colombia \\ (e-mail: jose.agudeloto@amigo.edu.co) \\ (2) Facultad de Ciencias Administrativas, Económicas y Contables, Univ. Católica Luis Amigó, Trans 51a \\ 67B-90, Medellín-Colombia (e-mail: farley.rojasre@amigo.edu.co) \\ (3) Vicerrectoría de Docencia, Univ. de Antioquia, Cl. 67 53-108, Medellín-Colombia (e-mail: \\ edgar.ocampo@udea.edu.co) \\ (4) Facultad de Educación y Humanidades, Univ. Católica Luis Amigó, Trans 51a 67B-90, Medellín-Colombia \\ (e-mail: sclavijo@funlam.edu.co)
}

${ }^{*}$ Autor a quien debe ser enviada la correspondencia

Recibido Ene. 15, 2018; Aceptado Mar. 21, 2018; Versión final Abr. 19, 2018, Publicado Oct. 2018

\begin{abstract}
Resumen
El objetivo del presente artículo es reflexionar sobre las relaciones que se trenzan y se imbrican entre el quehacer de la evaluación escolar y las posturas éticas que se presentan entre los diversos agentes involucrados en el acto mismo de valorar. Para ello se planteó una investigación de corte cualitativo, se tuvieron en cuenta importantes referentes teóricos y se examinaron, utilizando una matriz de análisis categorial, las apuestas evaluativas de treinta y dos instituciones de educación básica y media. Entre los hallazgos más importantes de la investigación se advierten: la relación directamente proporcional que existe entre un adecuado ejercicio valorativo y la postura ética que poseen los agentes educativos inmersos en dicha praxis, la necesidad de resemantizar de manera continua, la génesis y la teleología de la evaluación escolar. Se concluye también que se debe promover la aproximación sistémica de la evaluación y transformar los resultados evaluativos en una oportunidad de aprendizaje.
\end{abstract}

Palabras clave: evaluación escolar; educando; escuela; maestro; ética

\section{About School's Evaluation and its Ethics}

\begin{abstract}
This article presents a reflection and discussion on the relationship that is combined and overlapped between the task of school's evaluations and the ethical position that exist among the different actors involved in the act of assessing itself. To do this, a qualitative research was proposed that considered important theoretical authors and discussed the evaluative designs of thirty-two elementary and secondary schools, using matrix analysis. Among the most important findings of the research are; the directly proportional relationship that exists between an accurate assessment exercise and the ethical stance that possess the educational agents engaged in this practice, the need to continue re-semanticising, and the genesis and the teleology of the school's evaluation. In is also concluded that the assessment systemic approach must be promoted and that assessment results must be transformed into a learning opportunity.
\end{abstract}

Keywords: school assessment; student; school; teacher; ethics 


\section{INTRODUCCIÓN}

En estos tiempos contemporáneos, donde nada pareciera escapar al devenir propio del mundo, las preguntas por la enseñanza y por la evaluación de los aprendizajes, resultan no ser ni ajenas ni distantes a dicha movilidad. Resemantizar entonces las connotaciones de evaluación que habitan en la escuela, así como las prácticas valorativas que en el aula imperan, se constituyen en reto y en emergencia de la reflexión pedagógica actual. De este modo, Marcelo y Vaillant (2015), afirman la imperiosa necesidad de formar maestros sabedores de la movilidad y la volatilidad propia de los currículos contemporáneos, indicando que la problemática de la evaluación ha de estar inmersa en dicha versatilidad. Las posibilidades y las oportunidades de comprender la evaluación, no como un mero instrumento de verificación, ni como una práctica lineal establecida entre aquel que enseña y aquellos que aprenden; exhorta tanto a los neófitos maestros del presente, como a los experimentados maestros del ayer, a generar nuevas visiones, nuevas metáforas y neófitas prácticas valorativas; todas ellas en pro de una acertada, prudente y ética práctica evaluativa en el ámbito escolar. En este sentido Ariza (2014), sostiene que un adecuado ejercicio valorativo también convoca a repensar estados de alta calidad en la escuela contemporánea. Comprender entonces, tal como lo enuncia Toranzos (2014), que reducir la evaluación a un instrumento que responda a la compleja pregunta del “¿Qué enseñar?” no sólo empobrece la reflexión y la acción misma de evaluar, sino que enajena a los sujetos convidados a ser partícipes de dicho ejercicio. En esta misma lógica, nos resulta menester considerar que las estrategias de devolución y retroalimentación de todo ejercicio valorativo, tal como lo expone Ravela et al. (2014), han de ser una oportunidad de aprendizaje, con tanta o quizá más importancia que el diseño y la posterior aplicación de un determinado instrumento evaluativo.

Actualmente las políticas educativas sobre la evaluación escolar otorgan la posibilidad, a todas las instituciones educativas, de crear sus propios Sistemas Institucionales de Evaluación de Estudiantes (SIEE); es decir, les confiere elementos de autonomía y libertades prácticas para pensar y pensarse como territorios cercanos al aprendizaje. La evaluación no es entonces una mera respuesta por el conocimiento, sino más bien una oportunidad y una pregunta por el acto mismo de conocer. Esta idea nos recuerda, en gran medida, la postura asumida por Mélich (2016), quien afirma que el imperativo jimítame! resuena por todas partes, especialmente en los procesos educativos; pero acto seguido, aparece otro: ¡no me imites!

Entendiendo entonces la evaluación como un asunto dinámico y en constante transformación, resulta apenas pertinente comprender los nuevos lenguajes de la misma, sus nuevos sentidos y significados, sus neófitos movimientos y, por supuesto, las nuevas formas en que la escuela y los actores que en ella convergen, han de replantear y replantearse una nueva postura ética frente al ejercicio propio de la evaluación escolar. De ahí que asuntos como el clima escolar, evidenciado en elementos referidos a las percepciones de los educandos y los maestros, a las condiciones físicas y a las directrices institucionales, se constituyan en importantes variables al momento de la elaboración, el diseño, la aplicación y la posterior retroalimentación que ha de convocar toda práctica evaluativa, tal como lo refiere Aron et al. (2012). Así, se ha de entender que todo sistema valorativo, a la manera enunciada por Bolívar (2007), refiere un asunto organizacional, un sistema complejo en el que se tejen diversas relaciones y en el que todo proceso formativo, al igual que todo juicio emanado, habrá de rememorar, a la manera propuesta por Howe y Miramontes (1992), el ser ético que ha de habitar en todo quehacer evaluativo.

\section{METODOLOGÍA}

Se planteó una investigación de corte cualitativo la cual, tal como lo enuncia Niño (2011), propende por la comprensión integral de los fenómenos; en tanto provee de nuevas y potenciales oportunidades de indagación. A su vez, el paradigma asumido en esta investigación fue el histórico-hermenéutico, el cual ofertó una posibilidad de resemantizar las voces de los agentes exhortados a la investigación misma.

El proceso de recolección de información se desarrolló a partir de la lectura y posterior análisis de los Sistemas Institucionales de Evaluación de Estudiantes (SIEE) de 32 instituciones educativas de la ciudad de MedellínColombia, elegidas por criterios correspondientes a su naturaleza (16 instituciones públicas e igual número de instituciones privadas), ubicación geográfica y resultados en pruebas estandarizadas durante los tres últimos años. Luego, se realizó el diseño, la validación y aplicación de una entrevista estructurada a docentes y estudiantes, la cual constó de un total de diez preguntas, todas encaminadas al reconocimiento de las relaciones existentes entre una adecuada herramienta de evaluación y una conveniente postura ética del maestro y el educando. Los interrogantes esbozados en los instrumentos, pretendieron develar asuntos tales como: las prácticas evaluativas más recurrentes de los docentes, la utilización de los resultados como insumos de mejoramiento, la oportuna entrega de los resultados académicos, la postura de los educandos frente a la actividad evaluativa y la objetividad plasmada en los instrumentos empleados por los docentes. Es menester enunciar que la entrevista fue aplicada, a diez docentes y veinte estudiantes en cada institución, según criterios de permanencia, grado de formación y conocimiento del Sistema Institucional de Evaluación de 
Estudiantes (SIEE). De igual manera se realizó un grupo focal por cada una de las instituciones participes de la investigación. Para la interpretación de la información recolectada se creó una matriz de análisis categorial y se trianguló la información obtenida con diversa literatura especializada, propia y cercana al objetivo trazado en la investigación. Así mismo, resulta importante hacer alusión al manejo ético de la información otorgada por los invitados a la investigación, tratamiento que se evidenció en la implementación de consentimientos informados, en el uso responsable de la información y en el manejo respetuoso del nombre de los sujetos vinculados al proceso investigativo.

\section{LA CONCEPCIÓN DE ESTUDIANTE EN LOS SIEE}

Partimos de un supuesto, a saber, que los Sistemas Institucionales de Evaluación de Estudiantes (SIEE), tal como lo enuncia el Decreto 1290 de 2009 en su artículo 4ํ, se caracterizan precisamente por eso, es decir, por su naturaleza sistémica, por su carácter de institucionalidad, por su esencia evaluativa y por su teleología cercana a los procesos formativos de los estudiantes. De ahí que nos resulte entonces menester, y en procura de una sana indagación, re-pensar lo sistémico, lo institucional, lo evaluativo y la concepción de estudiante que se encuentra consignada en cada uno de ellos. Pensar lo sistémico de un Sistema Institucional de Evaluación de Estudiantes (SIEE) nos demanda, necesariamente, la resignificación de aquellas múltiples relaciones que se han de tejer y se han de imbricar entre todos aquellos sujetos inmersos en el acto mismo de evaluar; así, por ejemplo, conceptualizaciones cercanas a la medición lineal y distantes a las valoraciones multidimensionales de los sujetos evaluados, nos distancian de la connotación sistémica del denominado SIEE. De igual forma, resulta importante señalar la visión horizontal que soporta el espíritu del decreto y que sugiere una postura amplia y generosa para todos aquellos sujetos vinculados al ejercicio valorativo, recordando que la evaluación ha de permitir al sujeto evaluado, saberse como constructo de subjetividades; es decir, rememorando la necesidad de que en toda praxis valorativa emerjan y se potencien oportunidades de autoconocimiento, a la manera que lo expresa Sánchez (2013).

Un ejercicio evaluativo que no nace de una intencionalidad clara, que crece a la luz de la improvisación y fenece a la sombra de la univocidad, está realmente alejado de aquella acepción que conlleva y convoca el ser sistémico de la valoración. Y así, tal como lo esboza Mélich (2012), cuando afirma que los seres humanos no son nunca de un modo definitivo, se ha de advertir también que todo ejercicio evaluativo configurado en la escuela resulta ser ajeno a esa visión de absoluto que ofertó la modernidad. Las prácticas escolares que emergen de un determinado quehacer evaluativo convocan, forzosa e ineludiblemente, a deconstruir aquella acepción de cultura escolar que fue otorgada por la práctica evaluativa tradicional, en tanto exhorta a construir nuevas posturas éticas en la escuela. Recordando tal como lo advierte Schroder y Breuninger (2005), que ninguna identidad cultural emerge de la nada y que en cambio todas resultan ser construcciones colectivas, nacidas de la experiencia, de la tradición y de los anhelos propios de una comunidad determinada.

Los grandes esfuerzos individuales de todos aquellos sujetos quienes comparten con los niños y los jóvenes en las aulas de clase, claudican; una y otra vez, si no transforman en acto aquella relación de tejido y coresponsabilidad que le ha de ser propia a la escuela contemporánea. En consecuencia y en consonancia con lo expuesto por Velásquez et al. (2006), una adecuada práctica evaluativa ha de constituirse en regeneradora del tejido social que existe en el ámbito escolar; ella no habrá de interrogar única y exclusivamente por el conocimiento, sino que también habrá de apostarse por aquel sujeto que resulta ser hacedor y reconstructor de móviles saberes. En estas mismas lógicas Giroux (2016), recuerda que las estructuras de poder que emanan de la escuela no obedecen única y estrictamente a los discursos económicos que en ella coexisten, pues el discurrir académico, pedagógico y evaluativo, propio de la vida en la escuela, también genera sus propias prácticas.

Apelando entonces al numeral tres del artículo cuarto del Decreto en cuestión, que recuerda la importancia de pensar en estrategias de valoración integrales para los desempeños académicos de los estudiantes; se habrá de re-significar la pregunta y el cuestionamiento del quehacer del maestro. Maturana (2007), exhorta al sujeto contemporáneo a realizarse la siguiente pregunta: ¿Cómo hacemos lo que hacemos en tanto observamos nuestro hacer? Interrogante que, sin lugar a dudas y a la manera Socrática, habrá de constituirse en la génesis para erigir nuevas posturas éticas que ayuden a evidenciar aquella condición sistémica que ha de existir en la praxis valorativa. Así mismo, cuestionar y cuestionar-se por las complejas relaciones que se entrelazan entre los diversos agentes inmersos e involucrados en el acto de evaluar, se constituye en elemento de digna reflexión escolar, pues de esta enorme madeja, móvil y movilizadora, se desprenden diversos roles de poder, ansiedad, oportunidad, angustia y hasta fatalidad; elementos que también enuncian lo sistémico de la evaluación, en tanto nos recuerdan que el valor del conocimiento adquirido no puede juzgarse únicamente por su cantidad y su universalidad (Latorre y Suarez, 2000), pues su naturaleza desborda la dimensión cuantitativa y exhorta a pensar en sus aportes sociales, éticos, artísticos y culturales. El cuestionamiento del maestro por su propio quehacer le invita a la consecución de posturas críticas, a la vez que estimula aquella reflexión que emana del ejercicio de pensar, cuidadosa e inteligentemente, su propia 
praxis. "La inteligencia nos permite descubrir la naturaleza de las cosas, pero el pensamiento crítico es lo que nos compele a tomar partido por una explicación u otra, y de ese modo nos acerca a las razones y al sentido del universo" (Castellano, 2007).

No se trata de ubicar, única y exclusivamente, a los diversos entes que se hacen partícipes en el ejercicio de la evaluación, sino más bien de reconocer las posibilidades de relacionamiento que les son propias. Así, la pregunta sistémica por la evaluación no se reduce a encontrar el rol de los sujetos, sino que amplía su visión a las enormes y potenciales relaciones que entre ellos pueden generarse. Lo sistémico de la evaluación se constituye en emergencia de relación y en el volátil relacionamiento que se da entre los sujetos que de ella hacen parte. Recordamos así, la idea sostenida por Bertalanffy (1995), quien afirmó en su momento que un sistema podría ser definido como un complejo de elementos interactuantes entre sí.

La escuela, el aula, el sujeto, el saber, la cultura, el Estado y el currículo se hacen presentes en esa multidimensionalidad que, sin lugar a dudas, constituye ese ser sistémico de la evaluación; entramado que rememora lo expuesto por Koetz y Obino (2012), quienes advierten la necesidad de diseñar e implementar una acertada política pública - referida a la problemática de la evaluación escolar - que no dependa de la movilidad necia de un gobierno de turno, en cambio sea el fruto maduro de una consciente y honrosa práctica democrática. Así, toda práctica valorativa en la escuela habrá de tener en cuenta interrogantes tales como: (i) ¿Cómo podría realizarse una acertada praxis evaluativa sin tener clara la visión de hombre que demanda la escuela contemporánea?; (ii) ¿Quién podría diseñar una evaluación ética, responsable y respetuosa, sino se reconoce así mismo como sujeto evaluable en continua deconstrucción?; (iii) ¿Qué es lo que confiere a un hombre el poder de enseñar a otro hombre? (Steiner, 2004); (iv) ¿Qué contenidos, qué historias y qué identidades reivindicar? (Terrén, 1999); y (v) ¿Qué tipo de ser humano se pretende formar? (Flórez, 2005). Estos y otros tantos cuestionamientos emergen, potencian, transforman y movilizan el "ser" del maestro en el aula, en tanto dinamizan su "ser" de maestro evaluador en la escuela. De manera que es a la base de la pregunta por la otredad y el cuestionamiento por aquello que se constituye en lo otro que se reconoce, en gran medida, el carácter sistémico de la evaluación y el sistémico quehacer que enmarca toda práctica de valoración escolar.

Con respecto a su institucionalidad, la escuela no es ajena a la movilidad del mundo, no le es lícito extraerse a todas aquellas realidades que en ella convergen, como tampoco le resulta válido el no auto-configurarse mientras pretende configurar el mundo que habita y aquel otro mundo que en ella coexiste. En su interior se ha de enseñar, tal como lo refiere Morín (2001), a formar en la comprensión, antes que en la acción de condenar; de manera que todo ejercicio evaluativo este en la vía de ayudar a humanizar las relaciones que se entretejen en sus más íntimos territorios. En la institucionalidad de la escuela el saber y el "saber hacer" de toda práctica valorativa, han de estar mediados por el "saber ser" en el mundo de la realidad, de tal manera que lo expuesto por Ahumada (2005), nos recuerde que la escuela es ese universo donde la demanda y la interpelación por el ser del otro....se constituya en la interpelación y la demanda del sujeto por sí mismo.

Su institucionalidad es su capacidad de ser para con el hombre, que ella y en ella se transforma, mientras ella misma se permite "ser" permeada por todas aquellas metamorfosis. En estos tiempos móviles, dicha movilidad habrá de ser también su institucionalidad. La escuela no es un lugar para tallar la piedra, es más bien un lugar para labrar el alma; es un escenario para recordar, mientras nos recordamos, que lo que nos hace humanos es precisamente ese saber-nos en humanidad. Ella pretende hacer-nos comprender, a la manera expresada por Blejmar (2007), que el aprendizaje es, en definitiva, lo que nos permite hacer mañana lo que hubiera sido imposible realizar hoy. ¿Dónde radica entonces la institucionalidad de un SIEE, sino en el lograr vincular al sujeto a todo ese entramado y complejo mundo de la escuela y la evaluación? ¿En qué consiste el éxito de un SIEE, sino es en su capacidad para establecer diálogos, abiertos y sinceros, entre aquellos sujetos que son partícipes e implicados en el implicado y partícipe mundo de la evaluación? ¿Cómo comprender en nuestras instituciones educativas que la fuente del devenir y el cambio incesante se encuentra en la contradicción y no en la pasividad propia del consenso"? (Cerda, 2000).

Ahora bien, nuestras instituciones educativas y la institucionalidad que les ha de ser propia, no se hallan únicamente enmarcadas en planos de legitimidad; pues en ellas conviven, emergen y se potencian innumerables tensiones entre el deber ser y el "ser" que les ha de resultar propio. La institucionalidad del SIEE se advierte y se ve enunciada en los siete numerales del artículo octavo del Decreto 1290; artículo que sugiere elementos tales como la definición, la aprobación, la socialización, la incorporación y la divulgación del Sistema Institucional de Evaluación de Estudiantes a toda la comunidad educativa. A este respecto, resulta menester formular los siguientes interrogantes: (i) ¿Cuántos SIEE son diseñados, construidos y aplicados a la espalda de todos aquellos que serán sujetos de la evaluación en la escuela?; (ii) ¿Con qué palabras, con qué metáforas estamos comprendiendo la evaluación en ininteligibles SIEE que pretenden evaluar a los estudiantes?; y (iii) ¿Qué criterios de fiabilidad y honestidad pueden ofrecer-nos algunos SIEE, cuando la connotación de sujeto y sujeto evaluable brillan por su ausencia? 
La tradición evaluativa nos convoca a pensar y a pensar-nos en esferas de poder, donde aquel quien formula los interrogantes pareciera poseer acaso un rol más importante y decisivo que aquel otro quien ha de dar y de generar alguna respuesta. Un adecuado SIEE, en cambio, y convocando el espíritu del Decreto, habrá de asemejarse a ese lugar donde los diversos agentes evaluativos han de poder establecer diálogos y trenzar conversaciones entre quien pregunta y quien responde, entre quien enseña y quien aprende; convirtiendo así al ejercicio mismo de evaluar en oportunidad de aprendizaje. La práctica evaluativa en la institucionalidad, no puede reducirse a un mero ejercicio de comprobación, como tampoco puede reducirse el aprendizaje al uso de una fría y huraña lista de chequeo. La evaluación escolar, entendida como "ayuda pedagógica" (Lacueva, 1997), clama por ser invitada a nuestras escuelas, en tanto el sujeto que en ella coexiste comprenda que ayudar es un verbo cercano al reto y a la posibilidad que se erige en la reflexión académica contemporánea. En estas mismas lógicas Agudelo (2016), nos convoca a pensar que sin la existencia de preguntas móviles y con la presencia de respuestas fijas, el aprender se torna en un acto de enajenación.

El ejercicio de valorar, propio del sujeto que se sabe y se reconoce como pieza clave en el complejo engranaje de la institucionalidad escolar, ha de ser sabedor de que la evaluación se constituye en dispositivo estratégico que atraviesa y moldea la construcción de conocimiento en el aula (Perassi, 2008). Así, resulta claro a nuestro entender que existen diversos elementos comunes a todos los SIEE, a saber, todos ellos poseen un valor nomotético; pero también nos convocan a la tarea de advertir ese valor ideológico de los mismos, es decir, ese ser únicos, ese ser para ellos como institución diferente y diferenciadora, ese constituirse como SIEE que recuerda, a la manera en que lo enuncia Santos (1994), que todo lo que sucede en la escuela tiene significado y que por ende ha de ser, menester y pertinente, plantear ciertas cuestiones: (i) ¿Cómo se lee, se escribe, se evalúa, se interpreta, se vive y se mejora ese ser institucional que le sirve de impronta, única y diferente, a la escuela contemporánea?; (ii) ¿Quiénes comparten ese ser institucional y cómo se vincula a todos aquellos que son de otros sentires?; (iii) ¿Qué es lo realmente valorado, como institucional, en nuestras institucionalizadas escuelas?; y (iv) ¿Cómo generar escuelas donde los resultados sean consecuencias del cultivo de la humanidad y no el fin último de alguna extraña y foránea evaluación de turno?

La institucionalidad de nuestras escuelas es una construcción aunada y cooperativa de todos aquellos sujetos que en ella cohabitan, es el objetivo común que se trazan todas las humanidades que en ella convergen; pero también es la ciega obediencia que allí se imparte; también, es ese lenguaje, sumiso y dependiente, que en ella se ofrece y es a su vez comprado por algunos incautos mercachifles de conocimientos. La institucionalidad de la escuela no se da única y exclusivamente por decreto o por mandato, ella se da, además, por todo aquello que se gesta, por todo aquello que nace y se transforma, mientras otros tantos asuntos le construyen y le deconstruyen paulatinamente. La institucionalidad es esa práctica de "ser" que se da siendo en la escuela, es ese lugar de tensión y posibilidad que se halla entre el deseo de ser y la real posibilidad de ser en tanto se "es". De seguro, tal como sostiene Skliar (2007), la tristeza de la lengua escrita, es también la tristeza de la educación, cuando aquella no logra transformar al sujeto que le habita, le coloniza y le deconstruye. Sin lugar a dudas resulta más conveniente aprender cuando se tiene un buen maestro, cuando se cuenta con ambientes propicios para el ejercicio del saber, cuando los discursos de aquellos que enseñan son de un discurrir contemporáneo y hábil; pero, sobre todo, se aprende más cuando se "es" reconocido, cuando se "es" valorado y cuando en el acto mismo de la valoración se permite "ser" en completud. El holismo que le es propio al espíritu humano no podría serle ajeno a la escuela, pues en dicho distanciamiento se perdería, no solo el fin mismo de la institución escolar, sino también la teleología de la práctica evaluativa que le ha de considerar. Una verdadera evaluación educativa nos recuerda, con valor y vehemencia, que el saber es siempre un saber para saber "ser" (Santos, 1996).

A su vez, ser estudiante es ser sujeto de valoración en la institucionalidad de la escuela, es ejercer la condición de "ser" siendo, en un lugar que ha de permitir y posibilitar dicha condición. La genuina y auténtica pregunta por el sujeto ha de transversalizar toda la vida escolar, pues es en la escuela donde este cuestionamiento se torna en génesis de reconocimiento y principio de común-unidad. Así, las existencias y los resultados en la escuela no son una consecuencia algorítmica, fruto de la sumatoria de todos aquellos que son y son evaluados, sino más bien el conjunto de relaciones, móviles e inestables, de todos aquellos que se permiten ser mientras que anhelan ser valorados. ¿Qué emergencias nacen entonces de las complejas relaciones que se dan entre lo sistémico, lo institucional y lo valorable en un SIEE?; ¿Cómo potenciar desde un ejercicio valorativo amplio, generoso y honesto; a los sujetos implicados en el acto mismo de valorar?; ¿Quién, sino un sujeto reconocido como tal, podrá ser partícipe activo en un proceso de valoración constante, enmarcado en principios éticos? ; La existencia de estos y otros tantos interrogantes crecen en la escuela, se validan en su institucionalidad y se valoran en un adecuado y ético ejercicio evaluativo. No deberían existir vacíos entre lo sistémico, lo institucional y la connotación de educando que habitan y coexisten en un quehacer evaluativo. Así, lo develado en la lectura y análisis concienzudo de los SIEE y su respectiva confrontación con la realidad de la escuela, pone de manifiesto la necesidad de re-significar las imbricadas relaciones, vastas y complejas, que se tejen entre el conocimiento y los sujetos convocados a transformarle. Es menester en este aparte 
recordar, tal como lo enuncia Agudelo (2016), que las intencionalidades de todo ejercicio valorativo develan el "ser" del maestro y procuran nuevas voces al "ser" del educando.

Cada esfuerzo por construir un SIEE se constituye en una visión de escuela, en una perspectiva de comprensión de aquellos procesos que habitan y conviven en el ejercicio valorativo y cotidiano del mundo mismo de la institución, en tanto convoca a realizar neófitas apuestas evaluativas. En cada uno de los SIEE coexiste, desde la perspectiva de Blejmar (2007), una tensión creativa, una brecha motivadora entre lo que tenemos y lo que aspiramos, una oportunidad para hacer evidente aquello que el lenguaje enuncia. Así, por ejemplo, resulta pertinente hacer mención de aquellos SIEE que abren y posibilitan nuevas y emergentes interpretaciones de mundo, de valor, de escuela y de aquellas valoraciones que en ella se potencian; pero también resulta menester denunciar aquellos otros SIEE que parecieran conformarse con el acatar y el acatarse, sin reflexión alguna, a un decreto que exhorta al acto mismo de reflexionarse. El pretender pensar que, si todo está legislado poco importa el nivel de autonomía (Santos, 1994), se transforma inequívocamente en una anestesia para la creatividad del maestro y se aleja, por mucho, de la visión emancipadora de una evaluación que crece a la sombra y al amparo de la que habrá de ser una valoración honesta, intencionada y con criterios transparentes y generosos.

La postura institucional que se lee en la terminología, en la conceptualización y en la filosofía de cada SIEE, no puede ser contraria al despliegue del texto mismo; así por ejemplo, nos ha de resultar claro que si el documento que nos convoca, es decir, cada SIEE, no logra generar un impacto en la comunidad, impacto que se hace carne en la cultura institucional que de él se desprende y a quien dicha cultura nutre y transforma, entonces estamos frente a letra muerta; pues, sin lugar a dudas, se hace evidente que una cultura valorativa no se impone por decreto, sino que se construye en el despliegue del hacer viva aquella letra que en él se interpreta. Ningún SIEE puede agotarse en su valor hermenéutico, palidecer en su descripción de le realidad escolar y sucumbir ante una tímida y temerosa comprensión del complejo proceso que significa evaluar; pues verdaderamente es en el ejercicio interpretativo, en la práctica descriptiva y en el acto de valorar, donde se constituyen aquellos asuntos, móviles y movilizadores, que conforman aquel entramado de realidades que denominamos escuela. Es menester que la evaluación escolar, comprendida como proyecto, proceso y valoración (Santos, 1994), sea asumida por todos los agentes que en ella convergen, pues sin temor a equivocación alguna, se ha de afirmar que, tanto en nuestras escuelas como en nuestras contemporáneas sociedades, la actitud cooperativa no puede dejarse al devenir de una actitud cercana al capricho y a la improvisación. Así, pretender entonces conocer a los sujetos que evaluamos resulta ser tan importante como pensar, diseñar y construir unos adecuados instrumentos de valoración. El interrogante por las características de los educandos está consagrado en el espíritu mismo del Decreto que nos convoca, en tanto este hace referencia al universo particular de cada sujeto.

El cuestionamiento por el "ser" del estudiante exhorta a todo maestro a liberar-se y desligar-se de una interpretación lineal del ser del sujeto en la escuela, en tanto le exhorta a desplegar y a desplegar-se en el saber del sujeto mismo; rememorando la postura asumida por Mélich (2014), quien afirma que son precisamente, la perplejidad y la timidez del sujeto frente el quehacer del mundo de la escuela, los elementos que dan origen a las diversas posturas éticas que se experimentan en la escuela misma. La evaluación no es pues una simple y fría pregunta por el conocimiento que han de adquirir aquellos quienes escuchan e interpelan, sino más bien una evocación a preguntar-nos por el aprendizaje de aquellos que interpretan y transforman. La evaluación no es una mera respuesta por el conocimiento, sino una pregunta por el acto mismo de aprender; una invitación al "hablar-nos" que le es consustancial al sujeto y a la escuela en la que dicho sujeto cohabita. Así, evocamos a Heidegger (1987), cuando invita al hombre contemporáneo a construir una palabra para decir y decir aquella palabra que ha re-construido.

Nuestra concepción de evaluación, la práctica que de ella hagamos y el despliegue de dicho ejercicio en nuestras escuelas, han de evidenciar y evidenciarnos ese carácter sistémico de la misma, recordándonos que, tal como sostuvo Bertalanffy (1989), lo sistémico se constituye en un esfuerzo por representar determinados aspectos o panoramas de la realidad; aspectos que por supuesto encuentran puntos de imbricación y de relacionamiento mutuo. Así, la evaluación no puede ser ajena a las múltiples realidades de una escuela, de un país y de un mundo cada vez más entretejido, imbricado y complejo.

\section{DEL ROSTRO ÉTICO DE LA EVALUACIÓN}

Todo ejercicio valorativo y toda práctica escolar que propenda reconocer aquello que se "sabe", habrá de recordar, a la manera en que lo enuncia Mélich (2016), que el deseo no es simple apetencia, no es un capricho de esto o aquello; el deseo es deseo de alteridad nunca cumplido, sin límites, sin prohibiciones, el deseo sería imposible. Así, todo ejercicio valorativo, entendido como anhelo y aspiración por conocer, tendrá que recordarle a la escuela misma que en el acto de indagación, propio del deseo de saber cuánto se sabe, habrá de primar una postura ética, una actitud cercana al reconocimiento de la imposibilidad del saberlo "todo", un 
aporte que nos exhorta a pensar en la contingencia y en el devenir que le es propio al acto de la valoración ética que ha de construirse en la escuela. De ahí la posibilidad de concebir, a la manera de Eisner (2002), la evaluación como una obra de arte, como una praxis que describe, interpreta y valora, como aquel saber ético que se genera en el sujeto, en la escuela y en el ser del sujeto escolar.

La educación es un quehacer y un hacer ético, es una relación de respuesta al otro, un acto de visibilización de la otredad; en tanto el educador, en términos de Mélich (2012), es aquel apasionado por la transmisión, la voz y la valoración de aquellos sujetos inmersos en el mundo de la escuela. Así, todo ejercicio de evaluación conlleva una enorme posibilidad de decir una palabra nueva, de hacer una neófita lectura de la realidad y de exhortar a la realidad al mundo de la escuela. Lo auténtico, lo genuino y lo más valorable de todo proceso evaluativo habrá de ser, a la manera enunciada por Lévinas (1978), aquella capacidad de apreciar "el rostro" de todos los convidados a ser partícipes de la escuela. Difícilmente existirá una pregunta y una respuesta en la escuela, sino existe un sujeto real para cuestionar y un real sujeto para dialogar. El concepto de evaluación ética, discutido por Pérez et al. (2017), pareciera estar íntimamente ligado con el de evaluación continua; pues ambas acepciones hacen referencia a todo aquello que se realiza en el diario vivir de la escuela y que convoca, necesariamente, a la reflexión constante de la realidad. Postura que nos recuerda el enunciado de House (1997), quien recuerda que la validez en un ético ejercicio evaluativo, es aquella posibilidad de basarse en procedimientos objetivos, científicos y críticos, convocando siempre a la participación activa de los agentes convocados a dicho quehacer.

Que el sujeto piense mientras se piensa, aprenda mientras se aprehende y transforme mientras se transforma, resulta ser uno de los más importantes insumos para la praxis de la cotidianidad en la vida de la escuela. El ser del otro, su cercanía y su trayecto, su construcción de sentidos y significados han de recordarle al sujeto en la escuela que, tal como lo expuso Lévinas (2015), la proximidad de la otredad supera, por mucho, la distancia y el parentesco; la proximidad siempre recordará que el "ser" del otro también es responsabilidad del ser del sujeto en la escuela. Sí el tejido que se hace en el aula logra vincular contenidos académicos, estrategias pedagógicas, palabras, experiencias, visiones de mundo, tradiciones culturales y valoraciones intencionadas (Condemarín y Medina, 2000), se está frente a una real e intencionada evaluación escolar; con lo que el rostro ético de la misma queda en evidencia. En esta similar perspectiva Mélich (1997), incita a pensar que la autenticidad de la escuela y la legitimidad de todo acto evaluativo habrán de resultar cercanas al mundo de la vida. En consecuencia y ya que la práctica educativa invita a trabajar en un marco de incertidumbre y complejidad (Cabra, 2007), la labor del evaluador habrá de moverse en una racionalidad cercana al cambio y al devenir constante, pues es allí donde la práctica valorativa y las acepciones éticas encuentra su asidero y su subterfugio.

Los cambios en las actitudes y comportamientos, así como el fortalecimiento de la cultura organizacional, asuntos enunciados por Osorio y Rodríguez (2018), han de evidenciar una relación directamente proporcional con los resultados y los planes de contingencia que conlleva una práctica evaluativa escolar, ética e intencionada. En consecuencia, resulta menester que en la escuela contemporánea se cultive un espíritu de reflexión crítico, permanente y con un propósito pedagógico claro, a la manera en que lo sostienen Acebedo, et al., (2017). Ahora bien, esta teleología no es responsabilidad exclusiva de la escuela, pues el ámbito y el acompañamiento familiar de los educandos, así como la existencia de unas pertinentes políticas públicas sobre evaluación, tal como lo ha planteado Hernández et al., (2017), resultan necesarias para el despliegue de un ético quehacer valorativo. De igual forma y para efectos de advertir el entramado que se imbrica en todo ejercicio evaluativo, es menester pensar aquellos asuntos psicosociales que le son propios al docente, postura esbozada por Mosquera, et al., (2016), quienes advierten las relaciones que, desde allí, logra tejer el maestro con sus estudiantes, con la institucionalidad de la escuela y con aquellas políticas públicas que le recuerdan el tipo de hombre que, desde una visión de Estado, se desea ayudar a formar.

\section{CONCLUSIONES}

Las instituciones educativas, los maestros y los educandos, como agentes de cambio y transformación, deben repensar, continua e incansablemente, el por qué, el cómo y el para qué de la evaluación de aprendizajes, todo ello desde una perspectiva ética, donde se elijan metodologías y estrategias pedagógicas e intencionadas que permitan el ejercicio de un apropiado ejercicio valorativo. De igual forma es evidente la necesidad de realizar un adecuado diseño, una oportuna aplicación y una interpretación científica de los resultados, de manera que estos se comuniquen asertivamente y se transformen en ejes generadores de planes de mejoramiento continuo. Planes que han de ser pensados, construidos y desarrollados desde perspectivas en espiral, no desde posturas verticales y punitivas.

Así mismo se devela que la génesis, la aplicación y la teleología del Decreto 1290 de 2009, por el cual se reglamenta la evaluación del aprendizaje, le resulta desconocida a muchos de los sujetos partícipes e 
implicados en el complejo ámbito de evaluar; con lo cual se advierte la necesidad de redimensionar el ser sistémico de la evaluación. En estas mismas lógicas, la investigación evidencia la necesidad de transitar de una concepción punitiva de evaluación, a una dimensión que permita comprender la valoración escolar como cultura de mejora y oportunidad de aprendizaje.

Lo expuesto en este trabajo también exhorta a vincular en todo ejercicio valorativo, propio del ámbito escolar, factores tan importantes en los procesos de aprendizaje como: el trabajo colectivo, el equilibrio entre lo académico y lo emocional, la hermenéusis constante de los resultados, la comprensión de la evaluación como elemento constitutivo de un proceso, las neófitas imbricaciones entre los conceptos de evaluar e investigar y por supuesto, la cercanía que ha de existir entre la praxis valorativa que se realiza en la escuela, pública o privada, y la correspondiente postura ética de todos aquellos que le cohabitan y le deconstruyen.

\section{REFERENCIAS}

Acebedo Afanador, M., I. Aznar Díaz e L. Hinojo, Instrumentos para la Evaluación del Aprendizaje Basado en Competencias: Estudio de caso, Información Tecnológica, 28(3), 107-118 (2017)

Agudelo Torres, J. F., El cuento como estrategia pedagógica: una apuesta para pensar-se y narrar-se en el aula, Fondo Editorial Luis Amigó, Medellín, Colombia (2016)

Ahumada, P., Hacia una evaluación auténtica del aprendizaje, Editorial Paidós, México (2005)

Ariza, R., Formación de Docentes, El Gran Reto de la Calidad, Ministerio de Educación Nacional, Bogotá, D.C., Colombia (2014)

Aron, A., N. Milicic e I. Armijo, Clima Social Escolar: una escala de evaluación - Escala de Clima Social Escolar, ECLIS, Universitas Psychologica, 11(3), 803-813 (2012)

Bertalanffy, L., Teoría general de los sistemas, Fondo de Cultura Económica, México (1989)

Bertalanffy, L., Teoría general de los sistemas, Fondo de Cultura Económica, México (1995)

Blejmar, B., Gestionar es hacer que las cosas sucedan, Novedades Educativas, Buenos Aires, Argentina (2007)

Bolivar, A., Los centros educativos como organizaciones que aprenden: promesas y realidades, La Muralla, Madrid, España (2007)

Cabra, F., La evaluación como práctica educativa. Pensando en el evaluador como educador. En: Serie ONPE, Documentos para una evaluación crítica, 4, pp. 39-55 (2007)

Castellano, H., El pensamiento crítico en la escuela, Prometeo, Buenos Aires, Argentina (2007)

Cerda, H., La evaluación como experiencia total. Logros-objetivos-procesos-competencias y desempeños, Cooperativa Magisterio, Bogotá, Colombia (2000)

Condemarín, M. y A. Medina, Evaluación Auténtica de los Aprendizajes. Un medio para mejorar las competencias en lenguaje y comunicación, Andrés Bello, Santiago de Chile (2000)

Decreto 1290 de 2009: "Evaluación del aprendizaje y promoción de los estudiantes de los niveles de educación básica y media", Diario Oficial 44.840, Bogotá, D.C., Colombia (2009)

Decreto 1860 de 1994, "Por el cual se reglamenta parcialmente La Ley General de Educación”, Artículo 20ํㅜ Plan Nacional de Desarrollo Educativo, Diario Oficial 41.214, Bogotá, D.C., Colombia (1994)

Eisner, E., La imaginación educativa: en el diseño y la evaluación de los programas escolares, Merril Prentice Hall, New Yersey, USA (2002)

Flórez, R., Pedagogía del conocimiento, McGraw Hill, Bogotá, Colombia (2005)

Giroux, H., La Educación Superior y las Políticas de Ruptura, Revista Entramados: educación y sociedad, Año 3, №3, 1526 (2016)

Heidegger, M., De camino al habla, Serbal-Guitard, Barcelona, España (1987)

Hernández, C., C. Cárdenas, P. Romero y M. Hernández, Los Padres de Familia y el Logro Académico de los Adolescentes de una Secundaria en Milpa Alta, Ciudad de México, Información Tecnológica, 28(3), 119-128 (2017)

House, E., Evaluación, ética y poder, Morata, Madrid, España (1997)

Howe, K. y O. Miramontes, The ethics of special education, Teachers College, Prees, New York, USA (1992)

Koetz, C.M. y F. Werle, Trajetória do sistema de avaliação do rendimento escolar do Estado do Rio Grande do Sul, http://dx.doi.org/10.1590/S0104-40362012000400004, ISSN: 0104-4036, Ensaio: Avaliação e Políticas Públicas em Educação, 20(77), 677-700, (2012)

Lacueva, A., La evaluación en la escuela: una ayuda para seguir aprendiendo, http://dx.doi.org/10.1590/S010225551997000100008, ISSN: 0102-2555, Revista da Faculdade de Educação, 23(1-2) (1997)

Latorre, H. y A. Suarez, La evaluación escolar como mediación: enfoque socio crítico, Orión, Bogotá, Colombia (2000) 
Lévinas, E., Ética e infinito, Machado Libros, Madrid, España (2015)

Lévinas, E., Totalidad e infinito, Ensayo sobre la exterioridad, Sígueme, Salamanca, España (1978)

Marcelo, C. y D. Vaillant, Desarrollo Profesional Docente, ¿Cómo se Aprende a Enseñar?, $1^{\text {a }}$ Ed., 22-49, Narcea, Madrid, España (2009)

Maturana, H., La objetividad, Un argumento para obligar, Jcsarz, Chile (2007)

Mélich, J., Del extraño al cómplice, Antropos, Barcelona, España (1997)

Mélich, J., Ética de la compasión, Herder, Barcelona, España (2010)

Mélich, J., Filosofía de la finitud, Herder, Barcelona, España (2012)

Mélich, J., La prosa de la vida, Fragmentada, Barcelona, España (2016)

Mélich, J., Lógica de la crueldad, Herder, Barcelona, España (2014)

Morín, E., Los siete saberes necesarios a la educación del futuro, Magisterio, Bogotá, Colombia (2001)

Mosquera, R., L. Parra y D. Castrillón, Metodología para la Predicción del Grado de Riesgo Psicosocial en Docentes de Colegios Colombianos utilizando Técnicas de Minería de Datos, Información Tecnológica, 27(6), 259-272 (2016)

Niño, M., Metodología de la Investigación, De la U., Bogotá, Colombia (2011)

Osorio, V. y M. Rodríguez, Modelo para la Evaluación de Programas de Ética Organizacional en Universidades, Información Tecnológica, 29(1), 59-70 (2018)

Perassi, Z., La Evaluación en Educación: Un Campo de Controversias, Coediciones: Ediciones del Proyecto y Ediciones LAE, San Luis, Argentina (2008)

Pérez Pino, M., J. Enrique Clavero, J. Carbó Ayala y M. González Falcón, La evaluación formativa en el proceso enseñanza aprendizaje, ISSN: 2077-2874, EDUMECENTRO, 9(3), 263-283 (2017)

Ravela, P., J. Leymonié, J. Viñas y C. Haretche, La evaluación en las aulas de secundaria básica en cuatro países de América Latina, ISSN: 1995-7785, Propuesta Educativa, (41), 20-45 (2014)

Sánchez, T., La evaluación educativa como dispositivo de constitución de sujetos, Revista Latinoamericana de Ciencias Sociales, Niñez y Juventud, 11 (2), 755-767 (2013)

Santos, M., Entre bastidores: El lado oscuro de la organización escolar, Aljibe, Málaga, España (1994)

Santos, M., Evaluación Educativa, Magisterio del Río de la Plata, Buenos Aires, Argentina (1996)

Schroder, G. y H. Breuninger, Teoría de la cultura, Fondo de Cultura Económica, Buenos Aires, Argentina (2005)

Skliar, C., La educación (que es) del otro: argumentos y desierto de argumentos pedagógicos, Centro de Publicaciones Educativas y Material Didáctico, Buenos Aires, Argentina (2007)

Steiner, G., Lecciones para maestros, Siruela, México (2004)

Terrén, E., Educación y modernidad, entre la utopía y la burocracia, Antropos, Barcelona, España (1999)

Toranzos, L., Evaluación educativa: hacia la construcción de un espacio de aprendizaje, ISSN: 1995-7785, Propuesta educativa, (41), 9-19 (2014)

Velásquez, M., M. Novoa y M. Mayorga, La organización escolar: punto de partida de la evaluación de los docentes, ISSN: 0121-5051, Innovar, 16(28), 93-110 (2006) 
